\title{
Reports from the DSM-V Work Group on Sexual and Gender Identity Disorders
}

\author{
Kenneth J. Zucker
}

Published online: 16 September 2009

(C) American Psychiatric Association 2009

\section{DSM Prolegomena}

Since the first edition of the Diagnostic and Statistical Manual: Mental Disorders was published in 1952 by the American Psychiatric Association (APA), the manual has gone through a series of revisions: DSM-II in 1968, DSM-III in 1980, DSM-III$\mathrm{R}$ in 1987, DSM-IV in 1994, and a text revision to the DSM-IV in 2000. For those with a sharp eye, one will note that, subsequent to DSM-I, the manual has had a slightly different name: Diagnostic and Statistical Manual of Mental Disorders.

Any clinician, researcher, or policy maker with an interest in psychiatric nosology is keenly aware that the publication of the DSM-III in 1980 was a watershed moment in contemporary psychiatry. By that time, the intellectual and institutional hegemony of psychoanalysis that had dominated the psychiatric landscape had lost some, if not most, of its grip (see Grob, 1991; Paris, 2005; Wilson, 1993). Sketchy psychoanalytic models of at least some psychiatric disorders that were described in the DSM-I and DSM-II were abandoned. The rather vague diagnostic descriptors were replaced by more detailed criteria and, for the majority of conditions described in the DSM-III, an atheoretical approach predominated. As noted in the Introduction to the DSM-III:

For most of the DSM-III disorders...the etiology is unknown.... The approach taken in DSM-III is atheoretical with regard to etiology or pathophysiological process except for those disorders for which this is well established and therefore included in the definition of disorder.... The major justification for the generally atheoretical approach

K. J. Zucker ( $\square)$

Gender Identity Service, Child, Youth, and Family Program, Centre for Addiction and Mental Health, 250 College St., Toronto, ON M5T 1R8, Canada

e-mail: Ken_Zucker@camh.net taken in DSM-III with regard to etiology is that the inclusion of etiological theories would be an obstacle to use of the manual by clinicians of varying theoretical orientations, since it would not be possible to present all reasonable etiological theories of each disorder... Because DSM-III is generally atheoretical with regard to etiology, it attempts to describe comprehensively what the manifestations of the mental disorders are, and only rarely attempts to account for how the disturbances come about... This approach can be said to be "descriptive" in that the definitions of the disorders generally consist of descriptions of the clinical features of the disorders. (American Psychiatric Association, 1980, pp. 6-7)

A psychiatric nosology that was, by and large, agnostic with regard to underlying causal mechanisms was deemed preferable to a theoretical model that was no longer satisfying to many researchers and practitioners. Advances in biological psychiatry, the emergence of competing psychologic models of development and disorder, and the increasing availability of alternative approaches to therapeutics all contributed to a paradigm crisis in the discipline's nosological manual. Since 1980, one overarching vision was that the manual, if organized around descriptively neutral diagnostic criteria, could be utilized by a diverse array of clinicians and researchers from many disciplines. A common and transparent language, so it has been held, should facilitate communication in a rapidly developing field (see Spitzer \& Klein, 1978).

There was also another very crucial issue that served as a backdrop to the substantive changes that occurred with the publication of DSM-III, namely the concern that the prior manuals lacked sufficient detail to produce reliable and valid diagnostic categories. This was already apparent in the 1960s (e.g., Spitzer, Cohen, Fleiss, \& Endicott, 1967; Spitzer, Fleiss, Burdock, \& Hardesty, 1964; Stoller \& Geertsma, 1963), but was 
brought to the fore by the seminal work by a team of psychiatrists at Washington University in St. Louis (e.g., Feighner et al., 1972; Goodwin \& Guze, 1979; Robins \& Guze, 1970). The importance of reliability and validity has remained a central concern in all of the post-DSM-III manuals (see, e.g., Blashfield, Sprock, \& Fuller, 1990; Nelson-Gray, 1991; Pincus, Frances, Davis, First, \& Widiger, 1992; Tsaung, 1993; Widiger, Frances, Pincus, \& Davis, 1990; Widiger, Frances, Pincus, Davis, \& First, 1991) and will continue to do so with the publication of DSM-V.

For the last 30 years, it would be very reasonable to state the obvious: the DSM has had an enormous (international) impact on clinical training, the delivery of clinical care, and programs of research (both basic and applied). It has also served as a springboard for continued and considered reflection on the contemporary concept of mental disorder (see, e.g., Decker, 2007; Fabrega, 1994, 2006, 2007; Horwitz, 2002; Horwitz \& Wakefield, 2007; Houts, 2002; Jablensky, 2007; Jensen, Knapp, \& Mrazek, 2006; Kendell, 2001, 2002; Kendell \& Jablensky, 2003; Kendler, 1999; Lane, 2007; Lewis, 2006; Lilienfeld \& Marino, 1995; Luhrmann, 2001; McNally, 2001; Paris, 2008; Scotti, Morris, McNeil, \& Hawkins, 1996; Silk, Nath, Siegel, \& Kendall, 2000; Spitzer, 1999; Spitzer \& Endicott, 1978; Wakefield, 1992a, 1992b, 1993, 1997; Widiger \& Clark, 2000; Zachar $\&$ Kendler, 2007). At the time of completing this Editorial (August 30, 2009), the simple search term "DSM" in PubMed yielded a mere 28,223 entries!

\section{Back to the Future}

On April 13, 2006, the APA announced the appointments of David J. Kupfer, M.D., as chair, and Darrel A. Regier, M.D., M.P.H., as vice chair, of the DSM-V Task Force (American Psychiatric Association, 2006). And on May 1, 2008, the APA announced the appointments of the entire ensemble of the DSM-V Task Force (American Psychiatric Association, 2008), including the 13 Work Group Chairs for the current groupings of psychiatric disorders in the DSM-IV, its cross-cutting Work Groups, other members of the Task Force, and so on. Since then, many advisors have been nominated and approved by the Task Force to consult with the Work Groups, resulting in an even larger cast. The anticipated publication of the DSM-V is 2012, five years later than predicted by Blashfield and Fuller (1996). For further information on the DSM-V, the reader is encouraged to consult www.dsm5.org.

The DSM-V Task Force has, as its mission, a number of major tasks. These include, but are not limited to, the following: (1) literature reviews of current diagnostic entities; (2) literature reviews of proposed new diagnostic categories; (3) incorporation of feedback from advisors and the scientific community at large, as well as other interested stakeholders; (4) examination of relevant secondary data sets; (5) proposals for field trials to test revised diagnostic criteria; and (6) revision to the text that accompanies each diagnosis.

In addition, the Task Force will examine some other major issues: (1) the meta-structure of the manual, i.e., disorder groupings; (2) measurement of distress and impairment; (3) the possible inclusion of dimensional diagnosis as a complement to categorical diagnosis; (4) the possible inclusion of common dimensional assessment that will be used across different diagnostic categories; (5) further consideration of developmental parameters for diagnosis; and (6) further consideration of cultural factors and gender vis-à-vis diagnosis. For these issues, the interested reader can consult the following: Andrews, Charney, Sirovatka, and Reiger (2009), Beach et al. (2006), Dimsdale et al. (2009), Helzer and Hudziak (2002), Helzer et al. (2008), Hyman (2007), Kraemer (2007), Krueger, Skodol, Livesley, Shrout, and Huang (2007), Kupfer, First, and Regier (2002), Kupfer, Regier, and Kuhl (2008), Narrow, First, Sirovatka, and Regier (2007), Phillips, First, and Pincus (2003), Regier, Narrow, First, and Marshall (2002), Regier, Narrow, Kuhl, and Kupfer (2009), and Tackett, Balsis, Oltmanns, and Krueger (2009).

\section{The Sexual and Gender Identity Disorders Work Group}

It was an honor and privilege for me to be appointed as Chair of this Work Group by the DSM-V Task Force and the American Psychiatric Association. My first task was to consult with the Task Force regarding candidates for the Work Group. There was, of course, a restriction on how many members could be appointed to the Work Group. Vetting nominees is a timeconsuming process. It also costs money, as does participation in face-to-face meetings and conference calls. Thus, for our Work Group, as for others, it was impossible to consider all qualified candidates. Apart from consideration of scholarly qualifications, it was also important to adhere to the conflict of interest guidelines set forth by the Task Force, including a ceiling set on the amount of personal income received from the pharmaceutical industry (see Cosgrove, Krimsky, Vijayaraghavan, \& Schneider, 2006), an issue that was particularly relevant for our Sexual Dysfunctions subworkgroup. The Work Group that materialized included the following individuals: For the Sexual Dysfunctions subworkgroup, R. Taylor Segraves (Chair), Yitzchak M. Binik, Lori A. Brotto, and Cynthia Graham; for the Paraphilias subworkgroup, Ray Blanchard (Chair), Martin P. Kafka, Richard Krueger, and Niklas Långström; for the Gender Identity Disorders subworkgroup, Peggy T. Cohen-Kettenis (Chair), Jack Drescher, Heino F. L. Meyer-Bahlburg, and Friedemann Pfäfflin. Members of each Work Group nominated a number of advisors, many of whom are acknowledged in the literature reviews that are part of this Special Section of Archives.

In this issue (and already available via advance online publication), the reader will find a total of 16 reviews written by our Work Group. Reviews by Taylor Segraves on the male sexual 
dysfunctions will be published in the Journal of Sexual Medicine. Most of the reviews focus on a critical appraisal of the relevant diagnoses that appeared in the DSM-IV (or earlier), with proposed suggestions for reform and revision. There is also one review that considers the addition of a new diagnosis (Hypersexuality) and two reviews on gender identity disorder consider conceptual and sociopolitical/historical parameters. Each review was subject to internal feedback by the Work Group and, in some cases, from feedback by advisors. It should be made clear that the recommendations and options embedded in these reviews are just that. In no way should the reviews be considered the "final product." The final product is a multi-layered process that will involve additional feedback and certainly will be influenced by the results from field trials.

Publishing these reviews in the Archives is part of the transparency process that is of critical importance to the DSM-V Task Force. It allows interested members of the scientific community and other stakeholders to scrutinize the thinking of our Work Group and to provide feedback. In our post-modern era, where a micro-thought is just a twitter away, the scientific periodical is, I hope, still a useful forum for reflection, critique, and dialogue.

Commentaries that are no more than 1500 words in length will be considered for subsequent publication in the Archives. Commentaries should be submitted to Kenneth J. Zucker, Ph.D., Editor, Archives of Sexual Behavior at Ken_Zucker@ camh.net. The commentary should be submitted as an e-mail attachment using WORD, should contain a brief title, the author's complete mailing address, and the use of the reference style of the American Psychological Association.

Acknowledgment The author is the Chair of the DSM-V Work Group on Sexual and Gender Identity Disorders. Reprinted with permission from the Diagnostic and Statistical Manual of Mental Disorders V Workgroup Reports (Copyright 2009), American Psychiatric Association.

\section{References}

American Psychiatric Association. (1980). Diagnostic and statistical manual of mental disorders (3rd ed.). Washington, DC: Author.

American Psychiatric Association. (2006, April 13). APA appoints David J. Kupfer, M.D., and DarrelA. Regier, M.D., M.P.H. to headDSM-V Task Force [News Release]. (Available from press@psych.org).

American Psychiatric Association. (2008, May 1). APA names DSM-V Work Group Members: Experts to revise manual for diagnosis of mental disorders [News Release]. (Available from rroyce@psych.org).

Andrews, G., Charney, D. S., Sirovatka, P. J., \& Reiger, D. A. (Eds.). (2009). Stress-induced and fear circuitry disorders: Refining the research agendafor DSM-V. Arlington, VA: American Psychiatric Association.

Beach, S. R. H., Wamboldt, M. Z., Kaslow, N. J., Heyman, R. E., First, M. B., Underwood, L. G., et al. (Eds.). (2006). Relational processes and DSM-V: Neuroscience, assessment, prevention, and treatment. Washington, DC: American Psychiatric Publishing.

Blashfield, R. K., \& Fuller, A. K. (1996). Predicting the DSM-V. Journal of Nervous and Mental Disease, 184, 4-7.
Blashfield, R. K., Sprock, J., \& Fuller, A. K. (1990). Suggested guidelines for including or excluding categories in the DSM-IV. Comprehensive Psychiatry, 31, 15-19.

Cosgrove, L., Krimsky, S., Vijayaraghavan, M., \& Schneider, L. (2006). Financial ties between DSM-IV panel members and the pharmaceutical industry. Psychotherapy and Psychosomatics, 75, 154-160.

Decker, H. S. (2007). How Kraepelinian was Kraepelin? How Kraepelinian are the neo-Kraepelinians?-from Emil Kraepelin to DSM-III. History of Psychiatry, 18, 337-360.

Dimsdale, J. E., Xin, Y., Kleinman, A., Patel, V., Narrow, W. E., Sirovatka, P. J., et al. (Eds.). (2009). Somatic presentations of mental disorders: Refining the research agenda for DSM-V. Arlington, VA: American Psychiatric Association.

Fabrega, H. (1994). International systems of diagnosis in psychiatry. Journal of Nervous and Mental Disease, 182, 256-263.

Fabrega, H. (2006). Why psychiatric conditions are special: An evolutionary and cross-cultural perspective. Perspectives in Biology and Medicine, 49, 586-601.

Fabrega, H. (2007). How psychiatric conditions were made. Psychiatry, 70, 130-153.

Feighner, J. P., Robins, E., Guze, S. B., Woodruff, R. A., Winokur, G., \& Munoz, R. (1972). Diagnostic criteria for use in psychiatric research. Archives of General Psychiatry, 26, 57-63.

Goodwin, D. W., \& Guze, S. B. (1979). Psychiatric diagnosis (2nd ed.). New York: Oxford University Press.

Grob, G. N. (1991). Origins of DSM-I: A study in appearance and reality. American Journal of Psychiatry, 148, 421-431.

Helzer, J. E., \& Hudziak, J. J. (Eds.). (2002). Defining psychopathology in the 21st century: DSM-V and beyond. Washington, DC: American Psychiatric Publishing.

Helzer, J. E., Kraemer, H. C., Krueger, R. F., Wittchen, H.-U., Sirovatka, P. J., \& Regier, D. A. (Eds.). (2008). Dimensional approaches in diagnostic classification: Refining the research agenda for DSM$V$. Arlington, VA: American Psychiatric Association.

Horwitz, A. V. (2002). Creating mental illness. Chicago: University of Chicago Press.

Horwitz, A. V., \& Wakefield, J. C. (2007). The loss of sadness: How psychiatry transformed normal sorrow into depressive disorder. Oxford: Oxford University Press.

Houts, A.C. (2002). Discovery, invention, and the expansion of the modern Diagnostic and Statistical Manual of Mental Disorders. In L. E. Beutler \& M. L. Malik (Eds.), Rethinking the DSM: Psychological perspectives (pp. 17-65). Washington, DC: American Psychological Association.

Hyman, S. E. (2007). Can neuroscience be integrated into the DSM-V? Nature Reviews Neuroscience, 8, 725-732.

Jablensky, A. (2007). Does psychiatry need an overarching concept of "mental disorder"? World Psychiatry, 6, 157-158.

Jensen, P. S., Knapp, P., \& Mrazek, D. A. (Eds.). (2006). Toward a new diagnostic system for child psychopathology: Moving beyond the $D S M$. New York: Guilford Press.

Kendell, R. (2001). The distinction between mental and physical illness. British Journal of Psychiatry, 178, 490-493.

Kendell, R. (2002). The distinction between personality disorder and mental illness. British Journal of Psychiatry, 180, 110-115.

Kendell, R., \& Jablensky, A. (2003). Distinguishing between the validity and utility of psychiatric diagnoses. American Journal of Psychiatry, $160,4-12$.

Kendler, K. S. (1999). Setting boundaries for psychiatric disorders [Editorial]. American Journal of Psychiatry, 156, 1845-1848.

Kraemer, H. C. (2007). DSM categories and dimensions in clinical and research contexts. International Journal of Methods in Psychiatric Research, 16(Suppl. 1), S8-S15.

Krueger, R. F., Skodol, A. E., Livesley, W. J., Shrout, P. E., \& Huang, Y. (2007). Synthesizing dimensional and categorical approaches to personality disorders: Refining the research agenda for DSM-V 
Axis II. International Journal of Methods in Psychiatric Research, 16(Suppl. 1), S65-S73.

Kupfer, D. J., First, M. B., \& Regier, D. A. (Eds.). (2002). A research agenda for DSM-V. Washington, DC: American Psychiatric Association.

Kupfer, D. J., Regier, D. A., \& Kuhl, E. A. (2008). On the road to DSM-V and ICD-11. European Archives of Psychiatry and Clinical Neuroscience, 258(Suppl. 5), 2-6.

Lane, C. (2007). Shyness: How normal behavior became a sickness. New Haven, CT: Yale University Press.

Lewis, B. (2006). Moving beyond Prozac, DSM, and the new psychiatry: The birth of postpsychiatry. Ann Arbor: University of Michigan Press.

Lilienfeld, S. O., \& Marino, L. (1995). Mental disorder as a Roschian concept: A critique of Wakefield's "harmful dysfunction" analysis. Journal of Abnormal Psychology, 104, 411-420.

Luhrmann, T. M. (2001). Of two minds: The growing disorder in American psychiatry. New York: Alfred A. Knopf.

McNally, R. J. (2001). On Wakefield's harmful dysfunction analysis of mental disorder. Behaviour Research and Therapy, 39, 309-314.

Narrow, W. E., First, M. B., Sirovatka, P. J., \& Regier, D. A. (Eds.). (2007). Age and gender considerations in psychiatric diagnosis: A research agenda for DSM-V. Arlington, VA: American Psychiatric Association.

Nelson-Gray, R. (1991). DSM-IV: Empirical guidelines from psychometrics. Journal of Abnormal Psychology, 100, 308-315.

Paris, J. (2005). The fall of an icon: Psychoanalysis and academic psychiatry. Toronto: University of Toronto Press.

Paris, J. (2008). Prescriptions for the mind: A critical view of contemporary psychiatry. Oxford: Oxford University Press.

Phillips, K. A., First, M. B., \& Pincus, H. A. (Eds.). (2003). Advancing DSM: Dilemmas in psychiatric diagnosis. Arlington, VA: American Psychiatric Association.

Pincus, H. A., Frances, A., Davis, W. W., First, M. B., \& Widiger, T. A. (1992). DSM-IV and new diagnostic categories: Holding the line on proliferation. American Journal of Psychiatry, 149, 112-117.

Regier, D. A., Narrow, W. E., First, M. B., \& Marshall, T. (2002). The APA classification of mental disorders: Future perspectives. Psychopathology, 35, 166-170.

Regier, D. A., Narrow, W. E., Kuhl, K. A., \& Kupfer, D. J. (2009). The conceptual development of DSM-V [Commentary]. American Journal of Psychiatry, 166, 645-650.

Robins, E., \& Guze, S. B. (1970). Establishment of diagnostic validity in psychiatric illness: Its application to schizophrenia. American Journal of Psychiatry, 126, 983-987.

Scotti, J. R., Morris, T. L., McNeil, C. B., \& Hawkins, R. P. (1996). $D S M-I V$ and disorders of childhood and adolescence: Can structural criteria be functional? Journal of Consulting and Clinical Psychology, 64, 1177-1191.

Silk, J. S., Nath, S. R., Siegel, L. R., \& Kendall, P. C. (2000). Conceptualizing mental disorders in children: Where have we been and where are we going? Development and Psychopathology, 12, 713-735.

Spitzer, R. L. (1999). Harmful dysfunction and the DSM definition of mental disorder. Journal of Abnormal Psychology, 108, 430-432.

Spitzer, R. L., Cohen, J., Fleiss, J. L., \& Endicott, J. (1967). Quantification of agreement in psychiatric diagnosis: A new approach. Archives of General Psychiatry, 17, 83-87.

Spitzer, R. L., \& Endicott, J. (1978). Medical and mental disorder: Proposed definition and criteria. In R. L. Spitzer \& D. F. Klein (Eds.), Critical issues in psychiatric diagnosis (pp. 15-39). New York: Raven Press.

Spitzer, R. L., Fleiss, J. L., Burdock, E. I., \& Hardesty, A. S. (1964). The mental status schedule: Rationale, reliability and validity. Comprehensive Psychiatry, 10, 384-395.

Spitzer, R. L., \& Klein, D. F. (Eds.). (1978). Critical issues in psychiatric diagnosis. New York: Raven Press.

Stoller, R. J., \& Geertsma, R. H. (1963). The consistency of psychiatrists' clinical judgments. Journal of Nervous and Mental Disease, 137, 58-66.

Tackett, J. L., Balsis, S., Oltmanns, T. F., \& Krueger, R. F. (2009). A unifying perspective on personality pathology across the life span: Developmental considerations for the fifth edition of the Diagnostic and Statistical Manual of Mental Disorders. Development and Psychopathology, 21, 687-713.

Tsaung, M. T. (1993). From DSM-III-R to DSM-IV: Some reflections of process and method. Harvard Review of Psychiatry, 1, 126-128.

Wakefield, J. C. (1992a). Disorder as harmful dysfunction: A conceptual critique of DSM-III-R's definition of mental disorder. Psychological Review, 99, 232-247.

Wakefield, J. C. (1992b). The concept of mental disorder: On the boundary between biological facts and social values. American Psychologist, 47, 373-388.

Wakefield, J. C. (1993). Limits of operationalization: A critique of Spitzer and Endicott's (1978) proposed operational criteria for mental disorder. Journal of Abnormal Psychology, 102, 160-172.

Wakefield, J. C. (1997). When is development disordered? Developmental psychopathology and the harmful dysfunction analysis of mental disorder. Development and Psychopathology, 9, 269-290.

Widiger, T. A., \& Clark, L. A. (2000). Toward DSM-V and the classification of psychopathology. Psychological Bulletin, 126, 946-963.

Widiger, T. A., Frances, A. J., Pincus, H. A., \& Davis, W. W. (1990). DSMIV literature reviews: Rationale, process, and limitations. Journal of Psychopathology and Behavioral Assessment, 12, 189-202.

Widiger, T. A., Frances, A. J., Pincus, H. A., Davis, W. W., \& First, M. B. (1991). Toward an empirical classification for the DSM-IV. Journal of Abnormal Psychology, 100, 280-288.

Wilson, M. (1993). DSM-III and the transformation of American psychiatry: A history. American Journal of Psychiatry, 150, 399-410.

Zachar, P., \& Kendler, K. S. (2007). Psychiatric disorders: A conceptual taxonomy. American Journal of Psychiatry, 164, 557-565. 